\title{
Before Ghibli was Ghibli: Analysing the Historical Discourses surrounding Hayao Miyazaki's Castle in the Sky (1986)
}

Rayna Denison, University of East Anglia

\begin{abstract}
:
While Studio Ghibli may have become Japan's most important and successful animation studio, its early significance is far more debatable in relation to the success of its films. Normally viewed from the present moment, Studio Ghibli's brand significance is unmistakable, having become a producer of world renowned animation, and a distribution label for its own animated hit films and other high profile animation in Japan (Denison 2015). To challenge this perception of Ghibli's brand significance, this article revisits the early history of Studio Ghibli in order to examine the discourses around the formation of the studio. Using Studio Ghibli's first official film release, Castle in the Sky (Tenkū no shiro Lapyuta, 1986) as a case study, this article argues for a corrective analysis of the importance of Studio Ghibli to animator Hayao Miyazaki's first 'Ghibli' film. The article demonstrates that throughout this release, there was a tension between art and industry that would become the hallmark of Ghibli's style, but that the company itself may have had little to do with that brand's early conception.
\end{abstract}

Keywords: Studio Ghibli, anime history, Castle in the Sky, brand, advertising 


\section{Before Ghibli was Ghibli: Analysing the Historical Discourses surrounding Hayao Miyazaki's Castle in the Sky (1986)}

Rayna Denison, University of East Anglia

For more than two decades Studio Ghibli has been Japan's pre-eminent animation studio. As such, Studio Ghibli has emerged as a studio brand that represents a wide variety of products, from feature films to short animated films, to advertising campaigns for corporate partners and clients, to a studio museum and extensive merchandising. This broad spectrum of branded production in Japan has resulted in discourses around Studio Ghibli consistently flitting between oppositions of art and industry. I have argued elsewhere that this tension between art and industry means that 'Studio Ghibli' has developed significantly different meanings inside and outside of Japan, dependent upon the flows of its films and their promotion in different markets (Denison 2015). Alternatively, Thomas Lamarre, taking a textual view, argues that

Ghibli walks a fine line, between mass or generic appeal and an insistence on animation that, in the manner of high art or pure art, affords aesthetic distance and allows contemplation rather than thrills and observation. Out of this oscillation between mass art and high art emerges the brand, the Ghibli brand. (2009: 98 emphasis in original)

Lamarre's textual vision of the Studio Ghibli brand, like my own plural and industrial version, signals tension between the perceptions of Studio Ghibli films as art and industry. In other words, the expansiveness of Studio Ghibli's brand meanings act simultaneously as a testament to the company's global reach and also to its distinctiveness as a creative and industrial entity.

The tensions held within the brand, however, are not just a product of the current period, in which we are able to look back and reflect on what Studio Ghibli means as it becomes part of the history of Japanese animation production (however temporarily). The idea that Studio Ghibli has 'closed' is itself misleading. Instead of stopping, Studio Ghibli is now primarily functioning as a film producer, rather than creator, which can be seen in its latest co-production, The Red Turtle (La tortue rouge, Michaël Dudok de Wit, 2017) and it is still one of Japan's biggest distributors of world animation. Therefore, instead of assuming that Studio Ghibli's brand is a transhistorical entity, and now a thing of history, I want to 
examine the studio's historical trajectory, focusing on its earliest moments. To this end, I revisit the discourses around the film that was, officially at least, the first product made by Studio Ghibli: Hayao Miyazaki’s 1986 film Laputa: Castle in the Sky (Tenkū no Shiro Rapyuta, hereafter, Castle in Sky, the title it is best known for in English). Through this examination of Studio Ghibli's history, I argue that the company's earliest moments are marked by an intensification of the debates around art and industry that would coalesce in the Studio Ghibli brand later on.

Reconsidering the history of Studio Ghibli through the discourses around Castle in the Sky shows, on the one hand, how much remains to be learned about the history of animation in Japan, and, on the other hand, how high the stakes were for the filmmakers on the release of this film. Toshio Suzuki, the co-founder, CEO and head producer at Studio Ghibli (for more see Yoshioka, this collection), has written about how unusual Ghibli's standalone, feature film production strategy was in the 1980s, when most of the animated films being made were either adaptations of novels or manga, or theatrical versions of popular television shows (2011: 4). Concurring with Ryota Fujitsu's assessment of Ghibli's filmmaking strategy as 'high cost, high risk, high return' (2004: 205), I focus on how the promotional discursive surround for Castle in the Sky worked to manage risk (Klinger 1997). Through the use of contemporary discourse, I seek to demythologize Castle in the Sky's position within the history of Studio Ghibli, and to consider what this suggests about the early life of the studio. In doing so, Studio Ghibli is here viewed as a part of Japan's cultural industries (Hesmondhalgh 2007), whose discursive traces may reveal much about the place of studios within Japanese film and media culture.

Furthermore, I investigate how the discourses around the release of Castle in the Sky worked to explain the film's production process, the working practices of its creators and where Studio Ghibli fits within this narrative. Accordingly, I focus primarily on contemporary promotional interviews with core members of the production team, not least Hayao Miyazaki, as director, and Isao Takahata, who acted as his producer. However, I extend this analysis by analysing popular media discourses circulating around the time of Castle in the Sky's Japanese release, especially articles appearing in Japanese newspapers and in Animage magazine, a specialist anime magazine owned by Ghibli's parent company Tokuma shoten (Tokuma publishing). By revisiting these sources I look to reconstruct and analyse Castle in the Sky's original release in order to suggest that the tensions between art 
and industry that linger around Studio Ghibli's brand identity have always been a part of its success as a producer of popular 'art' animation.

\section{The 'first' Ghibli film?: From Nausicaä of the Valley of the Wind to Castle in the Sky}

The need to revisit Castle in the Sky's history is made obvious by the fact that there are still arguments over whether or not it is actually even Studio Ghibli's first film. The debate is first seen in scholarly accounts when Helen McCarthy declares that

After the success of Nausicä̈ of the Valley of the Winds [sic.], Miyazaki and Takahata set up their own production office and studio. Tenku no Shiro Laputa (Laputa, Castle in the Sky) was not the first production by Studio Ghibli, but it was the first in the style we have come to associate with the studio. (1999: 94)

It is worth noting that the production office McCarthy refers to is Nibariki, which Miyazaki and Takahata set up as a private office in the Suginami ward of Tokyo, which is famous for animation production. Studio Ghibli was set up separately some time later in 1985 . This is significant because, already, it is possible to see how Miyazaki and Takahata's companies were collapsed into 'Studio Ghibli' early in its English language criticism. What is more interesting here is that McCarthy is invoking a popular debate when she states that Castle in the Sky was not the first Studio Ghibli film. The debate seems to revolve around two separate issues: first, Studio Ghibli's own attempts to retroactively incorporate Hayao Miyazaki's first major hit film, Nausicaä of the Valley of the Wind (Kaze no tani no Naushika, 1984), under its distribution and brand labels; and, second, fans' and journalists' assessments that the relationship between Topcraft Studio and the formation of Studio Ghibli was more than just close (for more on the discussion by fans, see The Hayao Miyazaki Web). This latter debate is especially interesting simply because it has not entered into the academic scholarship around Studio Ghibli.

Regarding the first debate, which is primarily an industrial one, Nausica $\ddot{a}$ of the Valley of the Wind was produced by Tokuma shoten at the behest of the editorial staff at its Animage magazine, and so reflected much of the same ownership as Miyazaki's later films. Consequently, while scholarly Japanese sources routinely cite Castle in the Sky as the first Studio Ghibli film (Fujitsu 2004; Kanō 2006), the official Studio Ghibli website contradicts them by listing Nausicaä of the Valley of the Wind under its products (Studio Ghibli, n.d.). Although the Studio Ghibli website does make it clear that Studio Ghibli was founded after 
Nausicaä of the Valley of the Wind, it paradoxically also contends that Nausica $\ddot{a}$ was the 'first' film in the studio's official canon. Therefore, in Japan, as outside, this debate centres on important questions of rights and of the profits to be had from distribution. Studio Ghibli's distribution label, Jiburi ga Ippai (Full of Ghibli) distributes Nausicaä of the Valley of the Wind in Japan on Blu-Ray and DVD, and, consequently, making it part of the studio's chronology asserts the film's canonical status.1 This incorporation, by distribution and industrial history, creates industrial ambiguity around the status of Nausicaä of the Valley of the Wind, which alone among Miyazaki's many pre-Ghibli works has been fully canonised within the history of Studio Ghibli.

In the second debate, and perhaps as a consequence of the ambiguous rendering of Nausica $\ddot{a}$ of the Valley of the Wind's industrial status in Japan, transnational fans were quick to point to the industrial similarities between Topcraft studio, which produced Nausicaä of the Valley of the Wind, and the original composition of Studio Ghibli at the time of Castle in the Sky. The Hayao Miyazaki Web, an early and significant fan collective, argue that many of the animators working at Topcraft moved to the newly formed Studio Ghibli when Topcraft shuttered its feature film production studio mid-1985 (Team Ghiblink, n.d.). The overlap between personnel is significant - with Topcraft's Toru Hara acting as the first Studio Ghibli manager (Fujitsu 2004: 207), and with key animators like Yoshinori Kanada, Megumi Kagawa and colour designer Michiyo Yasuda joining Ghibli at this time from the defunct studio (for more, see Clements and McCarthy 2006). Aesthetically, then, most of Miyazaki's significant collaborative relationships are in evidence for Nausica $\ddot{a}$ of the Valley of the Wind; but, industrially, Miyazaki co-founded his Studio Ghibli at the behest of Tokuma shoten in 1985 only after that initial film's success. While the exact relationship between the closure of Topcraft and the formation of Ghibli remains somewhat obscure, what is interesting here is the way both debates suggest a commingling of aesthetic and industrial factors in Studio Ghibli's creation. The debates both revolve around aesthetics on one level - the sharing of personnel and the cohesion of aesthetics across a brand - while on another level, both debates can be clarified and better understood through an industrial lens.

Asserting that Nausicaä of the Valley of the Wind is Studio Ghibli's first film, however, lessens the significance of, and attention paid to, Studio Ghibli's other potential 'first' film: Castle in the Sky. In contrast to the debates outlined above, the advertising discourse at the time of Castle in the Sky's release made no reference to the new studio. However, it did heavily emphasize Nausicaä of the Valley of the Wind as an authenticating 
comparison point for Miyazaki's newest film. More immediate for audiences, and redolent with its own success and meanings, Nausica $\ddot{a}$ of the Valley of the Wind was used almost in place of a 'pre-sold' product or image for Castle in the Sky (Austin 2002; Brooker 2012). An example of newspaper advertising copy for Castle in the Sky proclaims that, 'A masterpiece is born that surpasses the thrills and excitement of Nausica $\ddot{a}$ of the Valley of the Wind!' (Studio Ghibli 2002: 155) In this way, the contemporary advertising sought to create links between these two films, while genre and a sense of artistic 'mastery' are also broadcast as surpassing Miyazaki's previous attempt at feature filmmaking.

The hyperbolic advertising discourse seen here also suggests that Nausica $\ddot{a}$ of the Valley of the Wind was something to be overcome, to be surpassed, through the artist merits and populist spectacle of Castle in the Sky. Unlike Jonathan Grey's (2010) claims about older texts creating intertextual shadows that threaten to overwhelm newer films, here Nausica $\ddot{a}$ of the Valley of the Wind is less of a threat, and more of an associated benchmark used to reassure potential audiences about the quality of production on Castle in the Sky. I would argue therefore that the attempts to incorporate Nausicaä of the Valley of the Wind into the Ghibli canon retrospectively have been about more than securing the legitimacy of Nausicaä's presence within Ghibli's history. At the time of Castle in the Sky's release, when Studio Ghibli was yet to become a known animation brand, Nausicaä of the Valley of the Wind was, instead, used as a generic and aesthetic example of the high quality audiences could expect from Miyazaki's work, as well as providing a benchmark against which Castle in the Sky could be judged.

The ambiguity around Studio Ghibli's formation and Castle in the Sky's production was heightened by the founders' explanations of the studio's history. For example, in an interview with Kinema Junpo, Japan's foremost film magazine, Miyazaki explains that

The truth is that after Nausicä̈ of the Valley of the Wind I wasn't in shape to direct, and I had planned to try to make a proper adventure animation, staged in a provincial city in Japan. Things were not coming together and flowing for the animation, and truthfully, I would still be in the middle of making it now, but it has become a documentary film. But now, the director is Isao Takahata, who is the producer on Castle in the Sky. (1986: 46)

The film under discussion became Takahata's The Story of Yanagawa's Canals (Yanagawa horiwari monogatari, 1987). The documentary's existence partially explains the creation of 
Nibariki because Miyazaki had put his profits from the Nausicaä of the Valley of the Wind manga into Nibariki in order to create a budget for Takahata's film (Miyazaki 2009), before the formation of Studio Ghibli.

As Toshio Suzuki explains, Takahata's documentary ran short of funds despite the budget supplied by Nibariki. In Suzuki's version of the founding of Studio Ghibli, Takahata's documentary became the main motivation for the production of Castle in the Sky: 'Takahata needed money to make The Story of Yanagawa's Canals. When Miya-san [Miyazaki] asked me about it, I proposed that, "The way ahead is simple. Let's make another film.” This was the start of Laputa Castle in the Sky.' (2005: 88) Takahata, however, suggests a different history in his interview for the promotional magazine Roman Album in 1986, where he claims that 'we proposed the new production studio asking, if Tokuma shoten has the view that after this we are going to be making real animation epics, ought we not to make it a nurturing place that is self-reliant?' (140) In this version, as elsewhere (Fujitsu, 2004), Tokuma shoten becomes the spur behind both the creation of the studio, and a source of pressure regarding what kind of films Miyazaki and Takahata should make.

Takahata suggests that they could have easily gotten funding for a Nausicaä sequel (Nausicaä Part 2, or Naushika Pāto 2), but that Miyazaki's insistence upon making a standalone film meant that, 'I was worried about whether we could do it on small production costs if it was a film for children. We had to make it as an epic amusement' (1986: 140). In this way, necessity dictated much of the production around Castle in the Sky, both in terms of needing to create a new studio where the work could be undertaken, and in regard of Tokuma shoten's pressure to create a film that would rival the success of their previous hit Nausica $\ddot{a}$ of the Valley of the Wind. In the accounts of the co-founders of Studio Ghibli, therefore, the impetus behind Studio Ghibli's genesis had more to do with economic necessity than art. Whether because they needed money to finish other projects, or because their financial backers were insisting upon bigger and bigger animated film successes, the founding of Studio Ghibli was tied to industrial imperatives, not just to the desire to make high quality animation.

\section{Miyazaki, intertextuality and the recycling of ideas in Castle in the Sky}

The result was a film that became highly intertextual. Like other forms of contemporary media, Japanese filmmaking is highly intertextual (Denison 2016), a tendency that developed early for animation. Marc Steinberg has shown that anime had already developed a 
sophisticated form of both intertextuality and paratextuality as early as the 1960s (2012). Although Castle in the Sky is routinely discussed in press coverage as a 'gensaku' or original work created by Miyazaki, it is also discussed as highly intertextual. Most obviously, Castle in the Sky's promotion clearly defined its generic identity, while allusions were made to European literature and Miyazaki's past work in animation in order to associate the new studio's film with perceived quality forms of children's literature and entertainment. This emphatic combination of generic language, recycling and borrowing is a sign of the complex systems of marketing present in 1980s Japan, as well as hinting at risk inherent in producing standalone films like Castle in the Sky. The games being played within the marketing of Castle in the Sky thereby reveal the potential difficulty in selling Miyazaki's artistic vision in the period of Japanese film history that preceded Studio Ghibli's well-known brand identity.

Miyazaki was clear about the generic identity for his new film, repeatedly referring to it as a 'bōken katsugeki', or action adventure film, throughout the promotional discourse created in the months leading up to Castle in the Sky's release. Even before that, in the original proposal for the film, Miyazaki calls it an 'intensely thrilling classic action film' (Miyazaki 2009: 252) and later he declares that 'The story unfolds like a roller-coaster ride, with love and friendship between the boy and girl developing on one level, and an action adventure focusing on the levitation crystal and trip to the castle in the sky taking place on another' (253). This highly generic set of descriptions is useful in uniting the disparate elements of the story, while giving the film a clear generic identity that was repeatedly linked back to the broader shōnen (boys') genre of anime by Miyazaki (Kinema Junpo 1986).

The action adventure genre aspect of Castle in the Sky is also connected back to Miyazaki's inclusions of intertextual borrowing. Borrowing from both the literary traditions of European and recycling character tropes and themes that Miyazaki had been experimenting with in his pre-Ghibli work, Castle in the Sky made its claim to 'epic amusement' through appeals to familiar, generic and yet inventive aesthetics intended to entice audiences. As Lamarre notes

It is not a question of straightforward continuity or direct influence. [...] Nonetheless, in Castle in the Sky, Miyazaki gathers those [previous] worlds into one epic world with a distinctively Miyazaki look and story arc. Castle in the Sky marks the emergence of a distinctive Miyazaki-Ghibli world and worldview, and in a stable and marketable form. (2009: 59) 
I would go further, and suggest that, in Castle in the Sky, we can see a compendium of Miyazaki's previous interests as an animator, and that, moreover, these interests played significant roles in the film's presentation to potential audiences.

Two facets to Miyazaki's intertextual referencing are particularly worthy of note: overt ones that were cited in the promotional materials surrounding the film's release; and covert ones that were a product of long-standing themes and interests. In relation to the latter, Lamarre makes careful note of the continuities between Castle in the Sky and earlier Miyazaki film and television productions. For example, Lamarre analyses how Future Boy Conan's (Mirai shōnen Konan, 1978) young female protagonist, Lana, mirrors Castle in the Sky's female heroine, Sheeta, both of whom are fighting against military forces trying to capture potentially destructive technologies (2009: 58). Other overlaps might also be suggested, for example, the fact that Miyazaki had worked as a key animator on Yasuo Ōtsuka's Gulliver's Space Travels (Garibā no uchū ryokō, also called Gulliver's Travels Beyond the Moon, 1965) when working at Tōei Animation. It is these repetitions that suggest Miyazaki was becoming a recognised animation auteur, not least thanks to his presentation as such in marketing materials. To put it another way, these repetitions can be thought of as linking Miyazaki's previous films and television shows to Castle in the Sky as way of authenticating the quality of its content, and demonstrating a generic consistency within the director's works.

Amongst the covert allusions to Miyazaki's own work, other more overt intertextual overlaps can be found. Miyazaki's pre-existing familiarity with Gulliver's Travels (1726) by Jonathan Swift, for example, became a central touchstone for discussions of intertextuality in Castle in the Sky. However, even Miyazaki's selection of Gulliver's Travels as a source text is shown to be part of more complex tapestry of intertextuality within the film's promotional coverage. In an Asahi Newspaper article, for instance, Miyazaki states that 'I thought we might make a work like Stevenson's Treasure Island. However, because it would be uninteresting to just use an island, I borrowed the idea of the floating castle of Laputa, which comes from Swift's Gulliver's Travels' (Asahi 1986). Miyazaki expands on his motivations in his interview for Kinema Junpo, recounting how:

I thought, why not make it something like Treasure Island? [...] and I thought it would be good to have an island floating in the sky [...] Certainly, I think it came out of Gulliver's Travels. In the proposal, when I wrote that it came from the third part of 
Gulliver's Travels, I was thinking that the older men who had not read it would probably think, 'ah, yes!' be persuaded. (1986: 43)

Miyazaki goes on to note that it was not until later that he learned of the unfortunate Portuguese language connotations of his chosen 'Laputa' title, which Swift had intended as an ironic name for his original castle.

The connection made above between Castle in the Sky and Swift and Robert Louis Stevenson's Treasure Island (1883) are important to the promotional for Castle in the Sky. On the one hand, Gulliver's Travels and Treasure Island are invoked as foreign literary authenticators for Miyazaki's fantasy action adventure film. On the other, they also connect Castle in the Sky to Miyazaki's previous work as an adaptor of foreign children's literature in animated television series. Most notable is the connection between Miyazaki's work with Takahata for the World Masterpiece Theatre animation series, which was comprised of adaptations like Akage no An (Anne of Green Gables, Isao Takahata, 1979), taken from Lucy Maud Montgomery's novel of the same name (for more, see: Hu 2010). Consequently, literary associations and adaptation work were a familiar part of Miyazaki's oeuvre for Japanese audiences, and therefore the continuing visibility of source texts like Treasure Island and Gulliver's Travels need to be understood as not just an appeal to educated audiences, but also as a reaffirmation of Miyazaki's growing critical reputation as an animation auteur. More significantly, though, in this case, they helped to off-set the risks inherent in making a 'gensaku' or original production, creating ostensible Ur-texts for audiences (for more on the importance of pre-sold or Ur-texts for audiences see: Austin 2002; Wyatt 1994).

Miyazaki's reputation as a popular animator was also significant within the promotion for Castle in the Sky. For example, Mainichi Newspaper confers high status upon Miyazaki, arguing that he is Japan's answer to Stephen Spielberg, and relating how Castle in the Sky was a U-turn in animation history intended to capture child and adult audiences alike (Mainichi 1986). By contrast, Animage magazine focuses more on Miyazaki's past, relating that 'Lupin and Clarisse. Conan and Lara. Miyazaki seems to have made these into legendary meetings, and he thinks "for sure, the meeting is the number one thing a director should put effort into"' (Animage 1986a: 62). These allusions to Miyazaki's work on Castle of Cagliostro and Future Boy Conan also suggest that his popular work for previous television and film shows was significant to the presentation of Castle in the Sky, particularly, it would 
seem, to the romance between the two central characters as they meet. These specific allusions to past Miyazaki works, combined with comparisons to Hollywood filmmakers and more covert analyses of Miyazaki's repetitions of themes and concepts across his television and film work, helps to suggest an image of Miyazaki as animation auteur. However, more pragmatically viewed, many of these allusions and repetitions are just as likely to have been the product of Miyazaki having less than two years to produce Castle in the Sky, and a whole career's worth of stifled and half-expressed ideas that he could recycle from the work he had done for other directors. Within the promotion for Castle in the Sky, therefore, there is a sense of a commercial auteur at work (Corrigan 1991), one who was aware of the value of repetition and promotion of his own past works as he attempted to create a new studio-based home for his animation style.

\section{Not just Ghibli, or not yet Ghibli? Ancillary and epiphenomenal production around Castle in the Sky}

In addition to the confusions over the status of Castle in the Sky in the history of Studio Ghibli, and to the myriad repetitions, references and allusions associated with it, the industrial context of the film's release also suggests that there was a good deal of experimentation taking place to bolster the reputation of Miyazaki's latest 'masterpiece.' Two of these experiments are worth exploring in detail because they directly impacted on the film's release. First, the release of two 'new' episodes from Miyazaki and Kyōsuke Mikuriya's animated television series Sherlock Hound (Meitantei Hōmuzu, or Famous Detective Holmes, 1984-1985) that were screened in cinemas along with Castle in the Sky. Second, a campaign for 'Laputa' soft drinks run by Ajinomoto. These two experiments offer insights into a counter-narrative to that of Miyazaki-as-auteur, again emphasising the split between art and industry at the heart of Ghibli productions and promotional surround. In the first instance, the use of Sherlock Hound shows that Miyazaki had yet to become an exclusively film-based auteur; while, the second example shows how Ajinomoto's attempts to create a real-world spectacle for its 'tie-up' campaign2 pulled the promotional focus away from Castle in the Sky and Miyazaki.

Sherlock Hound aired initially in 1984 on TV Asahi, and was a transnational coproduction between TMS and Italian broadcaster, RAI (Smith 2012). However, Sherlock Hound's production was complicated by 'a copyright dispute with Sir Arthur Conan Doyle's estate' (Team Ghiblink, n.d.) which may explain why some of the characters' names shift 
across the series, and why some of the episodes were re-released for cinematic exhibition with Nausicä̈ of the Valley of the Wind and Castle in the Sky where they acted as supplemental short films. The newspaper advertisements for Nausicaä of the Valley of the Wind indicate that its episodes were 'The Adventure of the Blue Carbuncle' (episode 5) and 'Treasure under the Sea' (episode 9), both of which were originally directed by Miyazaki (Studio Ghibli 2002: 124-139). For Castle in the Sky, two other Miyazaki-directed episodes, 'Mrs Hudson is Taken Hostage' (episode 4) and 'The White Cliffs of Dover' (episode 10) were presented as short films before Miyazaki's feature was shown.

The newspaper advertising for Nausica $\ddot{a}$ of the Valley of the Wind places greater emphasis on the presence of these episodes, with Sherlock Hound taking up about a third of the space in many advertisements (Studio Ghibli 2002: 124-135). However, the newspaper advertisements for Castle in the Sky tended to place the Sherlock Hound information at the bottom or in the corners of the advertisements. The diminishing size of the Sherlock Hound episodes is suggestive the rising popularity of Miyazaki’s feature films. Interestingly, too, the advertisements for Castle in the Sky call its episodes 'Zoku metantei Hōmuzu, ' literally meaning Famous Detective Holmes Continued, even though the original broadcast lists show that these were episodes taken from the middle of the original series. The Sherlock Hound shorts were, therefore, being treated as a series in their own right, despite the fact that audiences would have seen these episodes before. What these Sherlock Hound compendia add to the releases of Castle in the Sky and Nausica $\ddot{a}$ of the Valley of the Wind, is a pre-sold product repurposed for cinemas in the manner of popular summer anime 'roadshows.' Such roadshows regularly repurpose television animation for the cinema, and so were a fairly wellknown format even by the 1980s in Japan (Clements 2013; Clements and McCarthy 2006). The addition of Sherlock Hound episodes to cinematic exhibition of early Miyazaki films could therefore be seen as a mechanism to reduce risk, and in the case of Castle in the Sky, to add pre-tested products to an untested feature film.

For Castle in the Sky, the two episodes of Sherlock Hound were also used to expand the generic reach of the film. For example, an advertisement placed in Asahi Newspaper the day before Castle in the Sky's release displays the differences between the two films. The copy for Castle in the Sky declares that 'The Heart-warming Adventure Begins!' The strap line is then placed over a picture of protagonists, Pazu and Sheeta, in the air pirates' mechanical 'flaptor' machine, flying in front of the floating city-castle of Laputa. It explains that 'The young boy Pazu meets a mysterious girl who falls from the sky and they search for 
Laputa, beginning a journey that burns with courage and love... Go Pazu! Protect Sheeta...' (Studio Ghibli 2002: 160). Through this language and imagery the adventure and quest aspects of Castle in the Sky are unambiguously announced to audiences, as is the central focus on the male protagonist, something that contrasted to the female-centred story in Nausica ä of the Valley of the Wind. In the same advertisement, however, a smaller tagline reads, "An exciting romantic fantasy and love that surpasses "Nausicaa!"” promising audiences a balance of gendered interests (a boy protagonist, but romance; an adventure story, with a major female character and love). The taglines thereby work to balance generic associations and to eclipse Miyazaki's previous hit film. Accordingly, these descriptions of Castle in the Sky firmly place it within a set of genres as the successor to, and improvement upon, Miyazaki’s previous film.

Allied to the copy for Castle in the Sky, the advertisement contains the following statement about Sherlock Hound: 'An unbelievable big chase! Laughs so big it is absurd!' Here, the connection between chases and adventures may have been intended to conceptually unify the two sets of texts, but the emphasis on comedy also extends the generic reach of Castle in the Sky to include new potential audiences. In this way, the combination of Sherlock Hound and Castle in the Sky demonstrates a continuing release strategy in which the films of Hayao Miyazaki were allied with his work in television in order to maximize their potential reach in the Japanese marketplace. What they also show is that Miyazaki (and by extension Studio Ghibli) films were not yet a guaranteed draw for audiences. The recycling of Sherlock Hound into the exhibition of Castle in the Sky can therefore be read as a key means to off-set perceived lacks in Miyazaki's new feature film (comedy), while also reducing the risk inherent in creating an original and untested film.

Ajinotmoto's approach to supplementing and promoting Castle in the Sky went in a different direction. Toshio Suzuki has commented, years after the fact, that the 'Laputa' tieup (licensed product) campaign run by Ajinomoto was not particularly successful, even though it centred on the sale of a fruit-based soda in the middle of the hot Japanese summer (2005: 92-93, see also, Yoshioka, this collection). At the time, though, the campaign was extensive and high profile. It included multiple television commercials, large-scale prize draws and a competition to become a 'Laputa Reporter' in the Osaka area (Animage 1986a). The campaign received extensive coverage within Animage, where in addition to a making-of booklet on the production of the television commercials, Ajinomoto also took out multiple double-page spread advertisements (Animage 1986a and 1986b). However, Ajinomoto's deal 
with Studio Ghibli only allowed them to use Miyazaki's production sketches and the title logo for Castle in the Sky (Suzuki 2005). Ajinomoto responded by creating a series of live action of television commercials featuring a real-world model of Miyazaki's 'flaptor' design. The television campaign was initially focused on the Tokyo and Osaka metropolitan areas, and began airing from April $25^{\text {th }} 1986$, but it was further expanded following the film's release (Animage 1986b).

In August, the month of Castle in the Sky's release, the production of Ajinomoto's 'Laputa' soda campaign was covered in an extended booklet-length report in Animage. It explains that "The "Flaptor" is a type of aircraft that flaps its wings to fly through the open sky in this magnificent animated film' (Animage 1986b: 4), thereby introducing Ajinomoto's attempt to adapt Miyazaki's animated film into a live-action. In promoting their efforts, they announce:

Of course, while it may be true that this is a commercial for a tie-up product for anime film Laputa Castle in the Sky, which opens in August, the beauty does not come from remaking it [the film] as it is, as an anime film. It is constructed through live action special effects techniques. (Animage 1986b: 4)

This promotional coverage creates a hierarchical relationship between animation and liveaction production in Japan, suggesting that live action can reproduce, or even better, its animated counterparts. In this way, Ajinomoto's television commercial becomes, perhaps unintentionally, a rival for, instead of a complement to, or supplement to, Castle in the Sky.

This sense of competition is enhanced by the in-depth analysis of the production that follows in Animage's booklet. Some of those, like Hideo Hagiwara, the production designer on the commercials, attempt to complement Miyazaki; for example, saying that 'We paid attention to putting out the "antique image" which was there in Miyazaki's images,' when making his life-sized model of the Flaptor (Animage 1986b: 6). However, the director, Masatake Satomi, overtly compares his version and the forthcoming film. Satomi states that

On this job, the success of the moving wings was what I was most worried about, and the depth of field came out pretty well, and I think it turned out well. In the Laputa anime I have a lot of interest in seeing how the Flaptor flies, I'm looking forward to it. 
The remainder of the booklet focuses on the Flaptor model itself, including its length, width and weight, as well as providing a comparison of the mocked-up control panel and Miyazaki's original sketches for the machine. In this way, the coverage links the live-action production back to things Miyazaki was already becoming known for: namely, his machines. However, in emphasising the difficulty in producing the movements required to make the Flaptor fly, and by positioning live action spectacle and the real over Miyazaki's animation, Ajinomoto's commercial production team intimates that the real is more difficult, and therefore more worthy. In this way, the discourse around the commercial pulls focus away from the animated film and towards Ajinomoto's adaptation.

This emphasis on spectacle is such that other aspects of the commercial, including the characters' names (the actors are cited as Dennis and Diana, with no surnames supplied) are left out of the coverage in favour of emphasising the real-world challenge of producing Miyazaki's flying machine. The logic comes from both spectacle and expense. In the June 1986 issue of Animage (63) it was reported that the model had cost Ajinomoto 10million yen to manufacture, which was a significant investment by the tie-up producer on top of the expense involved in the filming process, which required new compositing equipment, bluescreen and camera cranes among other expenses. The fact that the promotional booklet for the television commercials (there were four versions of the ad in total, recut from the master footage), emphasizes the more spectacular aspects of the production process is perhaps understandable in this context. Spectacle is also drawn out of the voice-over narration for the commercials, which was recorded by the key voice actors from Nausica $\ddot{a}$ of the Valley of the Wind. The brochure attempts to surprise readers by telling them that 'Incidentally, Sumi Shimamoto (who play Nausicaä) and Yoji Matsumoto (who played Asbel) have been put in. What do you think?' (1986b: 4) In these ways, Ajinomoto's commercials competed with Miyazaki's new film, while spectacularly re-adapting aspects of his work into a live action context.

These peripheral experiments in marketing and exhibition around Castle in the Sky offer evidence that the industrial machinery of Studio Ghibli had yet to coalesce. Ajinomoto's campaign ran before Castle in the Sky's release, creating visual competition for Miyazaki's film, rather than simply re-using imagery from it to sell the Ajinomoto drinks product. Likewise, the episodes of Sherlock Hound were used to frame the viewing experience and advertising for Castle in the Sky, pulling attention away from the feature film even as the episodes were used to expand its generic meanings. 


\section{Conclusion}

Examined through its discursive promotional surround then, Castle in the Sky may have technically been Studio Ghibli's first film, but the way it was framed at the time does not suggest a break between this 1986 film and the earlier Nausicaä of the Valley of the Wind. Rather, the promotion and exhibition for Castle in the Sky repeated the seemingly successful practices used for Miyazaki's Nausicaä of the Valley of the Wind, and even the tie-up advertisers worked to make connections between both the 1984 and 1986 films. Furthermore, by the time Studio Ghibli was created, Miyazaki was already a significant animator, and one who was building an established style of filmmaking that could be recognised across production patterns in both his television and film productions. Having brought many of the key production staff across from Nausicaä of the Valley of the Wind to Castle in the Sky, this continuity in aesthetics was further exaggerated. For these reasons, Miyazaki's Castle in the Sky, despite being the first film created by Studio Ghibli, might be better thought of as more of a continuation, or consolidation, of his existing approach to filmmaking.

However, Castle in the Sky remains a significant moment of experimentation and risktaking for Miyazaki and Studio Ghibli. While it would not be the last time the Studio Ghibli released a double-bill, it was the last time Miyazaki's television work was repurposed for exhibition with his films. In addition, Suzuki changed his approach to tie-ups and licensing following the economic failure of Ajinomoto's expensive 'Laputa' soda campaign (2005, see Carter, and Yoshioka, this collection). The campaign ended up delivering a product with little connection to the film, to the extent that Ajinomoto struggled to sell the links between its citrus-fruit drink and Castle in the Sky. Ajinomoto's product information states that the Laputa drink 'is about as refreshing as the story, full of adventure and romance, and it will moisten the throats of a lot of people' while the company's tie-up advertisements temporarily rebranded Ajinomoto as 'Kazenomoto'. This new name implies the brand confusion riddling the Ajinomoto campaign, with the 'Kaze' of Kazenomoto being borrowed from the first word in the Japanese title of Nausicä̈ of the Valley of the Wind. Studio Ghibli's lack of either oversight or control regarding these changes suggests that the company was not yet able to exert the kinds of associative brand power that it would later come to wield (Denison 2015).

Likewise, although the prize draws Ajinomoto ran for Castle in the Sky contained goods branded with Miyazaki's original sketches for the film, they were not otherwise cognitively associated with its content, especially not when it came to the grand prize, a 
Toshiba home entertainment system, branded as a 'Laputa Version' system for the purposes of the prize draw (Animage 1986a: 46-47). In these ways, Castle in Sky's status is further confused and spread too thinly, becoming unthinkingly commercialized in a way that Suzuki would not repeat after Studio Ghibli became a more stable corporate entity.

This is perhaps the most significant point to be drawn out of the debates around whether or not Castle in the Sky is the 'first' Studio Ghibli film or not. Up until 1990, when Suzuki was able to convince Tokuma shoten that Studio Ghibli could be reimagined as a constantly staffed, permanent animation studio (Suzuki 2005; McCarthy 1999), Studio Ghibli remained a nascent, sporadic industrial construct. Fujitsu recounts that initially, 'To reduce the risk to the company, they decided on a basic policy of gathering staff to make each production, and then dissolving the group when finished' (2004: 207). Even in 1986, though, stability was Miyazaki’s aim. In his Kinema Junpo interview, Miyazaki claims that Studio Ghibli was created when 'we made a team by collecting scattered people together' and he goes on to say that 'if you are just paying for piecework, then you can't really call them your staff' (46). Later in the same interview Miyazaki goes on to outline his hopes for his studio:

Personally, I think about having the kind of place where the people I want to work with are here and have permanent jobs, even if I have to personally take in outside work and have no cooler in my house all summer. (Kinema Junpo, 1986: 47)

This is where the tension resides - the Studio Ghibli that would rise to prominence in the Japanese film industry was yet to be a reality in 1986, and its most famous animator's ambitions had yet to be realised. In an industrial sense, then, the debates around which film was the 'first' Studio Ghibli work might be easily extended into the years following Castle in Sky, into the 1990s and the construction of the first purpose-built Studio Ghibli offices and permanent staff.

Likewise, the tensions inherent in the definitions of Studio Ghibli's brand might be extended beyond art and industry into the contexts of the promotion and dissemination of their films. Examples like the partnerships with Topcraft, Ajinomoto and Tokuma shoten all indicate that Ghibli's corporate identity in this early period was fluid. Further, with the lack of permanent staff, Studio Ghibli was, in this period at least, only really discernible through its productions, forcing industry into the heart of aesthetic considerations of branding and studio identity. Before Studio Ghibli became what we know it as today, then, it was a far 
more contingent entity, reliant on the economic might and aesthetic skills of other institutions.

Moreover, Castle in the Sky's success was far from certain, and the repackaging of previously successful television hits demonstrates how much trepidation there was around releasing original animated films in a period led by the successes of animation on television (Clements 2013). In the experiments around Castle in the Sky's release and in its allusions to a wide range of intertextual materials and epiphenomenal supporting texts, we can see how essential a contextual understanding of Japanese film production is to a full understanding of the significance of Miyazaki and his nascent Studio Ghibli. Castle in the Sky, therefore, offers us a corrective lens through which the emergence of Studio Ghibli can be viewed, and reveals how crucial it is to understand brands as historically, contextually situated phenomena that are always-in-process. As Takahata, Miyazaki and Suzuki worked to create their studio, Castle in the Sky became their first attempt to draw together the threads of production, promotion and distribution that would later dominate the Japanese animation industry under the guise of Studio Ghibli.

Acknowledgements: I would like to thank the Great Britain Sasakawa Foundation for their generous support for this research. All translations are my own, unless otherwise indicated in the Bibliography. 


\section{Bibliography}

Animage (1985), 'Pirate Ship Tiger Moth,' [Kaizokusen Tigāmosugou], Animage 86.8, n.p. Animage (1986a), 'Castle in the Sky: Morning, A Young Girl Opens her Eyes in Pazu's Home,' [Tenkū no shiro Lapyuta: Asa, Pazū no ie de shōjo wa mezameta...], Animage 96.6, pp. 46-47 and 62-65.

Animage (1986b), 'Report on the Filming of the Laputa Commercial,' [Lapyuta CF satsuei repo], Animage 98.8, pp. 3-12.

Asahi (1986) 'Castle in the Sky the New Film from Director Hayao Miyazaki,' ['Miyazaki Hayao kantoku ga shinsaku Tenkū no shiro Lapyuta'], Asahi Newspaper 29 July, p. 11.

Austin, T. (2002), Hollywood, Hype and Audiences: Selling and Watching Popular Film in the 1990s, Manchester: Manchester University Press.

Brooker, W. (2012), Hunting the Dark Knight: Twenty-first Century Batman, London: IB Tauris.

Clements, J. and H. McCarthy (2006), The Anime Encyclopedia, Revised and Expanded Edition, Berkeley, CA: Stonebridge Press.

Clements, J. (2013), Anime: A History, London: BFI Publishing.

Corrigan, T. (1991), A Cinema Without Walls: Movies and Culture after Vietnam, New Brunswick, NJ: Rutgers University Press.

Denison, R. (2015), Anime: A Critical Introduction, London: Bloomsbury.

- (2016), 'Franchising and Film in Japan: Transmedia Production and the Changing Roles of Film in Contemporary Japanese Media Cultures,' Cinema Journal 55.2, pp. 67-88.

Fujitsu, R. (2004), 'A Studio Ghibli Walk,' [Sutajio Jiburi no ayumi,] Eureka 12, pp. 205217.

Grey, J. (2010), Show Sold Separately: Promos, Spoilers, and Other Media Paratexts, New York: New York University Press. 
Hesmondhalgh, David (2007), The Cultural Industries, Second Edition, London: Sage.

Hu, T.Y.G. (2010), Frames of Anime: Culture and Image-Building, Hong Kong: Hong Kong University Press.

Kanō, S. (2006), The Complete Hayao Miyazaki, [Miyazaki Hayao zensho], Tokyo: Film Art.

Klinger, B. (1997) 'Film History Terminable and Interminable: Recovering the Past in Reception Studies,' Screen 38.2: 107-128.

Lamarre, T. (2009), The Anime Machine: A Media Theory of Animation, Minneapolis: University of Minnesota Press.

Mainichi (1986), 'We Hear from Director Hayao Miyazaki of Castle in the Sky: An Anime U-Turn to Bestow Dreams on Children,' ['Tenkū no shire Lapyuta no Miyazaki Hayao kantoku ni kiku: Kodomo ni yume wo ataeru anime ni U-tān'], Mainichi Newspaper 6 August, sec.2, p.7.

McCarthy, H. (1999) Hayao Miyazaki: Master of Japanese Animation, Berkeley, CA: Stonebridge Press.

Miyazaki H. (2009), Trans. Beth Cary and Frederk L. Schodt. Starting Point 1979-1996. San Francisco: Viz Media.

Nomura M. (1986), 'Castle in the Sky: Interview with Director Hayao Miyazaki.' [Tenkū no shiro Laputa: Miyazaki Hayao kantoku intabyū.] Kinema Junpo 941, pp. 42-49.

Smith, I. R. (2012), 'Sherlock Hound and the Transnational,' Alluvium 1.3

https://www.alluvium-journal.org/2012/08/01/sherlock-hound-and-the-transnational/. Accessed 18 August 2016.

Steinberg, M. (2012), Anime's Media Mix: Franchising Toys and Characters in Japan, Minneapolis: University of Minnesota Press.

Studio Ghibli (2002), Have you Seen the 'Newspaper Advertisements'for Nausicä̈?

[Naushika no 'shimbun kōkoku' tte mita koto arimasuka?] Tokyo: Tokuma shoten and Studio Ghibli.

Studio Ghibli (n.d.), 'Studio Ghibli Chronology’ [Sutajio Jiburi nenhyō], Sutajio Jiburi, http://www.ghibli.jp/30profile/000159.html\#more. Accessed 01 September 2016. 
Suzuki, T. (2005), My Film Hobby, [Eiga dōraku], Tokyo: Pia.

— (2011) Ghibli’s Philosophy, [Jiburi no tetsugaku,] Tokyo: Iwanami publishing.

Takahata I. (1986) 'Producer Isao Takahata: I had Enjoyable Thoughts on Music Design and the Theme Song,' Roman Album Castle in the Sky [Tenkū no shiro Lapyuta] 1986 [Republished 2005], pp. 140-141.

Team Ghiblink (n.d.), 'Kaze no Tani no Naushika: Frequently Asked Questions,' The Hayao MIYAZAKI Web, http://www.nausicaa.net/miyazaki/nausicaa/faq.html\#studio. Accessed 23 August 2016.

Wyatt, J. (1994), High Concept: Movies and Marketing in Hollywood, Austin: University of Texas Press.

\section{Notes}

1 It is worth noting that this label also distributes other pre-Ghibli works like Miyazaki's Rupan Sansei: Kariosutoro no Shiro (Lupin III: Castle of Cagliostro, 1979), but does not include it within their studio chronology. In fact, Castle of Cagliostro is distanced from the main Ghibli distribution label by being repackaged as a 'Special', and stamped with a 'TMS Tokyo Movie Product' stamp that qualifies its status, and closeness, to the Ghibli brand. By contrast, incorporating Nausicaä of the Valley of the Wind fully into the Jiburi ga Ippai DVD label, confirms its canonicity.

2 Tie-up is the term commonly used in Japan to describe licensed tie-ins. In this instance, Suzuki had arranged for Ajinomoto to produce goods, a juice soda that would be linked to Castle in the Sky through sketches from the production and an advertising campaign. 